\title{
Component traits influencing seed yield in recombinant inbred lines of lentil (Lens culinaris Medik.)
}

\author{
Alok Kumar ${ }^{*}$, R. K. Gill and Sarvjeet Singh \\ Department of Plant Breeding and Genetics, Punjab Agricultural University (PAU), Ludhiana -141004 (Punjab), INDIA \\ "Corresponding author. E-mail: alokgupta.pau@gmail.com
}

Received: August 31, 2016; Revised received: January 24, 2017; Accepted: May 4, 2017

\begin{abstract}
One hundred and thirty five RILs (Recombinant Inbred Lines) developed from a cross between an indigenous and exotic line of lentil (Lens culinaris Medik.)were evaluated for seed yield and component traits during rabi 201213 and 2013-14. Pooled analysis of variance revealed significant differences among the RILsfor all the traits studied. This suggested that there was ample scope for selection of promising RILs for yield improvement in lentil. Phenotypic and genotypic coefficients of variation were high for pods per plant $(32.49 \%$ and $26.75 \%)$ followed by biological yield per plot(24.38\% and $21.28 \%$ ). Genetic advance was highest for 100 -seed weight $(47.75 \%)$ followed by pods per plant $(45.39 \%)$. Estimation of phenotypic correlation coefficients indicated that seed yield per plot expressed highly significant and positive correlation with biological yield per plot(0.634), harvest index $(0.300)$ and seeds per pod (0.156). Path coefficient analysis revealed that the traits; biological yield per plot, harvest index, number of pods per plant, days to $50 \%$ flowering, days to maturity , plant height and primary branches per plant had positive direct effect on seed yield per plot. The selection of these traits would be helpful for further yield improvement in lentil.
\end{abstract}

Keywords: Correlation, Genetic Variability, Lentil, Path analysis, Recombinant inbred line (RIL)

\section{INTRODUCTION}

Lentil (Lens culinaris Medik.) is a diploid selfpollinated crop considered to be one of the oldest crops of mankind having probable progenitor L. orientalis with Mediterranean as the centre of genetic diversity. It is second most important pulse crop of rabi season next to chickpea, primarily grown in central parts of India.It is mainly cultivated in Madhya Pradesh, Uttar Pradesh, Uttarakhand, Bihar, Orissa and West Bengal. Information on genetic variability and heritability is useful to formulate selection criteria for improvement of seed yield. Since lentil is primarily a rain fed crop, yield stability is a major objective in any breeding program. This could be achieved through a better understanding of the components contributing to seed yield. However, these components vary from year to year and from location to location, even for the same lentil genotype (Muehlbauer et al., 1994). Yield being the most important and complex trait is governed by polygenes and influenced by many physiological processes within the plant as well as affected by the environmental factors. The study of inheritance of various developmental and productive traits through the estimation of different genetic parameters like components of variances, genotypic and phenotypic coefficients of variability, heritability and genetic advance is helpful for framing an effective breeding programme. Selection is more effective for traits show- ing high heratibility and genetic advance. So, the knowledge of heratibility estimates alongwith other parameters acts as a useful guide to plant breeders (Kumar et al., 2015). Keeping above in view, the present study was planned to study variability and association between grain yield and component traits in Recombinant Inbred Lines (RILs) of lentil (L. culinaris Mediks) developed from crossing an indigenous line with an exotic line, possessing rust resistance.

\section{MATERIALS AND METHODS}

The material for present study comprised of one hundred and thirty five RILs developed from a cross involving a rust susceptibleold lentil cultivar, L9-12 and rust resistantadvanced breeding line from ICARDA (International Centre for Agricultural Research in Dry Areas), FLIP2004-7L. The two parents L9-12 (female) and FLIP 2004-7L (male) were crossed to generate $\mathrm{F}_{1}$ and $\mathrm{F}_{2}$ generation. The material was advanced from $\mathrm{F}_{3}$ to $F_{8}$ generations following single seed descent method to develop RILpopulation using off season facility. One hundred and thirty five RILs along with parents and two checks (LL699, LL931) were evaluated for seed yield and its component traits. All the 139 genotypes were sown in $22.5 \mathrm{~cm}$ wide paired rows of $1.5 \mathrm{~m}$ length in Alpha Lattice Design with three replications at Punjab Agricultural University (PAU) Ludhiana during rabi 2012-13 and 2013-14.PAU is located at $30.9^{\circ} \mathrm{N}, 75.85^{\circ}$ $\mathrm{E}$ and $256 \mathrm{~m}$ above sea level. The experimental 
location falls under sub-tropical zone with annual rainfall of $726 \mathrm{~mm}$. Standard package of practices were followed to raise the crop. Data for the morphological traits namely, daysto50 percent flowering, days to maturity, seed yield per plot, biological yield per plot and harvest index were recorded on plot basis whereas, for characters like number of primary branches, plant height, pods per plant, seeds per pod and 100-seed weight, the data were recorded from five randomly selected plants only. Data were subjected to statistical analysis to work out ANOVA(Analysis Of Variance), genotypic (GCV) and phenotypic (PCV) coefficients of variation, heritability and genetic advance as per cent of mean as per standard methods using SAS (Statistical Analysis System) software (SAS 1996). Genotypic and phenotypic coefficients of correlation were computed according to Al-Jibouri et al. (1958). The correlations were further partitioned into direct and indirect effects as suggested by Dewey and Lu (1959).

\section{RESULTS AND DISCUSSION}

Genetic variability is the basic requirement for any crop improvement programme. Extent of genetic variability is directly related to crop improvement, larger the variability more the chances of improvement for trait under question. A trait can be improved through selection if large amount of variability is present in the existing breeding material; otherwise breeder has to generate variability by various means such as acquisition of germplasm, hybridization or through mutation before taking up selection. The analysis of variance of 139 genotypes including 135 RILs, two parents and, two checks was carried for various morphological traits, seed yield and results are given in Table 1. The mean sum of squares for treatments were highly significant $(\mathrm{p} \leq 0.01)$ for all the characters which account for the genetic variability among the genotypes derived from the cross L9-12 $\times$ FLIP-2004-7L. Significant differences among the genotypes of lentil for various morphological traits such as; plant height, number of branches per plant and yield components were also observed earlier by Singla et al (2007)and Singh et al (2009) at PAU Ludhiana.The mean sum of squares for replicates was also significant $(p=0.01)$ for most of the traits except for days to maturity and 100-seed weight. Results of pooled analysis of variance also showed significant difference among the genotypes. The mean sum of squares of year $\times$ treatment interaction was also significant for most of the traits except primary branches, seeds per pod and 100-seed weight. This indicates genotypes responded differently in different environments in the present study.

The general mean, range and different parameters of genetic variability are presented in Table 2 . PCV was the maximum for pods per plant followed by biological

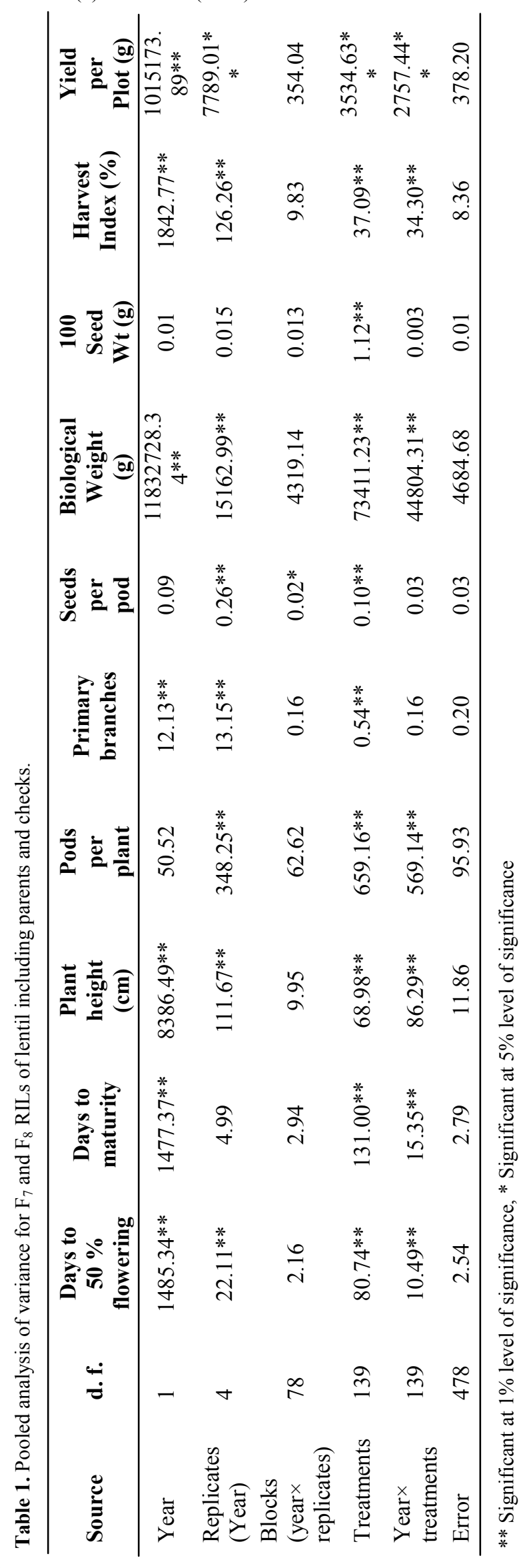


Alok Kumar et al. / J. Appl. \& Nat. Sci. 9 (2): 992 - 997 (2017)

Table 2. Genetic variability for seed yield and component characters in recombinant inbred lines of lentil.

\begin{tabular}{lcccccccc}
\hline Characters & Mean & Range & PCV (\%) & GCV (\%) & GM & $\mathbf{h}^{2}(\%)$ & GA & $\begin{array}{c}\text { GA of } \\
\text { mean (\%) }\end{array}$ \\
\hline Days to 50\% flowering & 100 & $96-113$ & 3.48 & 3.13 & 102.89 & 80.99 & 5.97 & 5.80 \\
Days to maturity & 142 & $134-156$ & 3.36 & 3.16 & 144.01 & 88.57 & 8.83 & 6.13 \\
Plant height (cm) & 35 & $27-45$ & 18.14 & 15.26 & 38.60 & 70.73 & 10.20 & 26.44 \\
Pods per plant & 50 & $25-78$ & 32.49 & 26.75 & 49.18 & 67.81 & 22.32 & 45.39 \\
Primary branches & 2.77 & $2-4$ & 16.34 & 8.77 & 2.66 & 28.77 & 0.26 & 9.69 \\
Seeds per pod & 1.68 & $1.2-1.9$ & 11.06 & 6.77 & 1.68 & 37.51 & 0.14 & 8.54 \\
Biological yield per plot (g) & 528 & $124-860$ & 24.38 & 21.28 & 645.02 & 76.20 & 246.89 & 38.28 \\
Harvest index & 24 & $18-33$ & 19.36 & 14.58 & 26.04 & 56.76 & 5.89 & 22.63 \\
100-seed weight (g) & 1.9 & $1.5-2.9$ & 23.73 & 23.45 & 1.96 & 97.67 & 0.93 & 47.75 \\
Seed yield per plot (g) & 130 & $20-195$ & 21.84 & 17.44 & 163.99 & 63.79 & 47.07 & 28.70 \\
\hline
\end{tabular}

yield and 100- seed weight, whereas days to $50 \%$ flowering and maturity had low estimates of PCV. Similar trend was observed for GCV for almost all the traits, though they were slightly low compared to PCV. These results were in conformity with the findings of Singh et al (2009). They also observed maximum value of PCV for pods per plant (34.37) followed by biological yield (29.09) in lentil germplasm at PAU Ludhiana. Selection is always favoured when a major proportion of a large amount of phenotypic variability is due to heritable variation. Heritability is a measure of genetic relationship between parent and progeny and has been widely used in determining the degree to which a character may be transmitted from parents to off-springs. In the present study heritability expressed as percentage ranged from 28.77 to 97.67 . Very high heritability estimates were obtained for 100 - seed weight $(97.67 \%)$,), days to maturity $(88.57 \%)$, days to 50 percent flowering $(80.99 \%)$ biological yield per plot $(76.20 \%)$ and plant height $(70.73 \%)$. Moderate heritability estimates were obtained for number of pods per plant $(67.81 \%)$, and seed yield per plot (63.79). whereas low heritability estimates were obtained for number of seeds per pod (37.51) and primary branches (28.77). Bicer and Sarkar (2008) evaluated diverse lentil genotypes in Turkey and reported high heratibility for days to flowering, 100seed weight and seed yield per plant.Though high heritability indicates the effectiveness of selection on the basis of phenotypic performance, it does not show any indication of the amount of genetic progress for selecting the best individuals. The genetic advance as per cent of mean was highest for 100-seed weight $(47.75 \%)$ followed by number of pods per plant (45.39\%) biological yield per plot $(38.28 \%)$ and seed yield per plot $(28.70 \%)$ which showed close association with the findings of Singh et al (2009). Moderate genetic advance estimates were obtained for plant height (26.44) and harvest index (22.63\%), which were in accordance with the findings of Singh et al (2012) who evaluated 245 lentil genotypes of lentil at Narendradev University of Agriculture and Technology (NDUA\&T), Faizabad and reported high GCV for seed yield per plant, 100- seed weight, pods per plant and harvest index. Kumar et al (2009)studied genetic variability in ninety five advanced $\left(\mathrm{F}_{6}\right)$ elite derivatives from microsperma $\mathrm{x}$ macrosperma crossesalong with five checks at Palampur, Himachal Pradesh. The study revealed sufficient variability for all the grain yield components except seeds per pod. They also reported high genetic advance for pods per plant, yield per plot, 100 -seed weight and harvest index in lentil. In the present study,low genetic advance was observed for days to 50 per cent flowering $(5.80 \%)$, days to maturity $(6.13 \%)$, number of seeds per pod $(8.54 \%)$ and primary branches $(9.69 \%)$. Lower genetic advance was also reported for days to 50 per cent flowering and days to maturity by Singh and Srivastava (2013) in field studies on eighty lentil genotypes at Varanasi. From the present investigation, it is clear that characters like seed yield per plot, pods per plant and biological yield per plot had high heritability and higher genetic advance which indicated that the expression of these characters is governed by additive gene action. So, these characters can be easily improved by selection methods. High heritability coupled with moderate genetic advance was expressed in plant height and harvest index. High heritability estimates and low genetic advance were obtained for days to 50 per cent flowering, days to maturity and 100 -seed weight implied that these traits are most probably governed by non-additive gene action.

Estimation of phenotypic correlation coefficients indicated that seed yield per plot expressed highly significant positive correlation with biological yield per plot (0.634), harvest index (0.300), seeds per pod (0.156), and plant height $(0.200)$ while it is significantly negatively correlated with 100 -seed weight $(0.205)$, days to flowering (-0.162), and days to maturity $(-0.127)$ in the present study. (Among the other traits, 


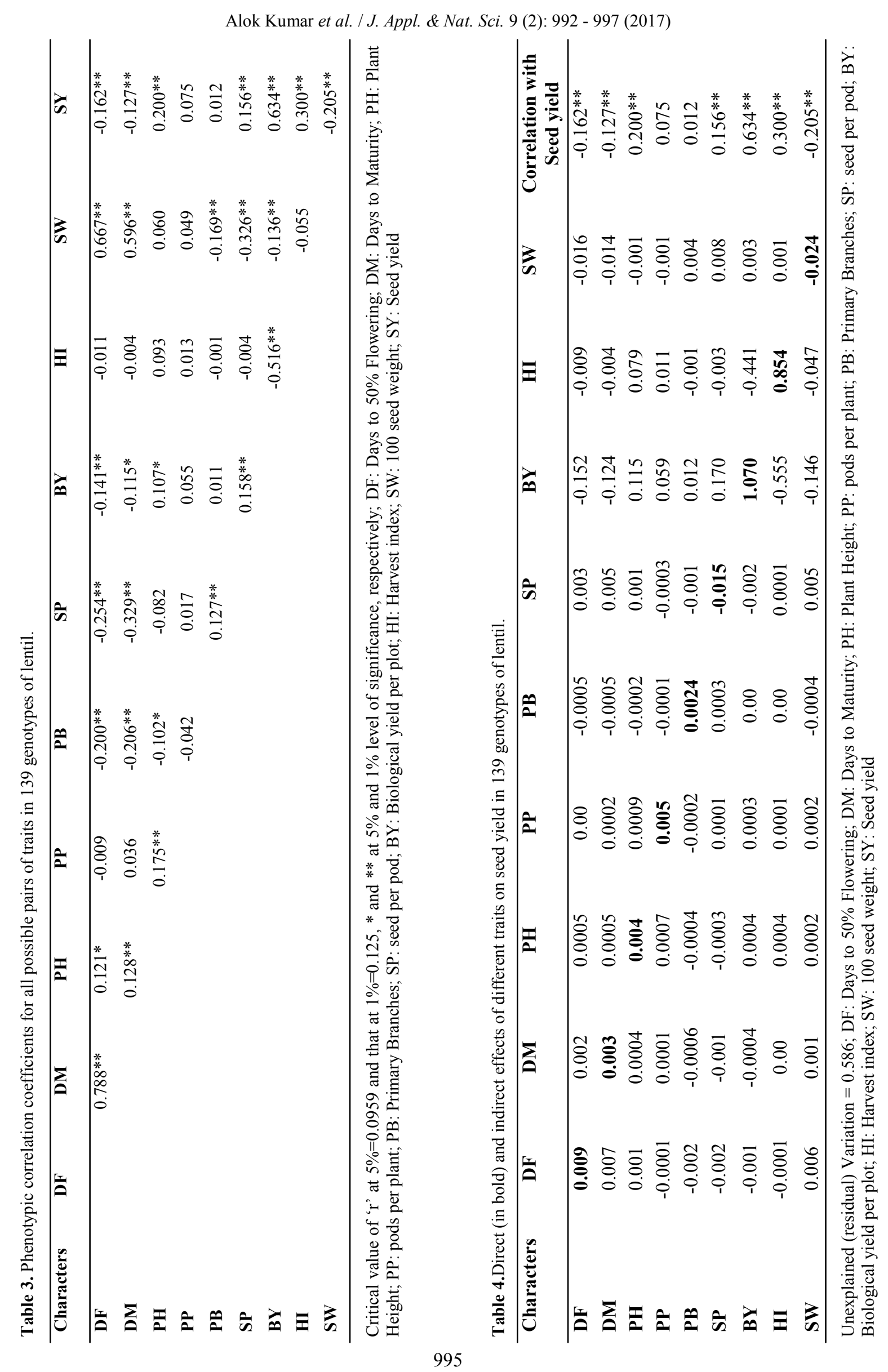


days to 50 per cent flowering had highly significant positive correlation with days to maturity (0.788), 100 - seed weight (0.667), and plant height (0.121) but highly significant negative correlation with seeds per pod (-0.254), primary branches and biological yield per plot. Days to maturity had positive significantly high correlation with 100 -seed weight (0.596), plant height $(0.128)$ but highly significant negative correlation with seeds per pod (-0.329) and primary branches. Plant height had highly significant positive correlation with pods per plant (0.175) and biological yield per plot (0.107). However, it had significant negative correlation with primary branches. Primary branches per plant showed significant positive correlation with seeds per pod (0.127). Pods per plant showed highly significant positive association with plant height $(0.175)$. Seeds per pod had positive significant correlation with primary branches $(0.127)$ and biological yield per plot (0.158) but highly significant negative association with days to maturity (-0.329), 100-seed weight (-0.326) and days to 50 percent flowering. Biological yield per plot recorded positive significant correlation with seeds per pod $(0.158)$ and plant height $(0.107)$ but it had significant negative association with harvest index $(-0.516)$ days to 50 percent flowering $(-0.141)$ and days to maturity (-0.115). Similar studies were conducted in lentil by Dalbeer et al (2013) at NDUA\&T, Faizabad. They observed significant positive correlation of seed yield $(p=0.05)$ with plant height, days to maturity, number of branches per plant, pods per plant and biological yield per plant.

Efficiency of selection in any breeding programme mainly depends upon the knowledge of association of characters. Although correlation coefficient indicates the nature of association among the traits but path coefficient analysis splits the correlation values into direct and indirect effects so as to measure the relative importance of causal factors involved. In present investigation, the path coefficient analysis on phenotypic basis (Table 3) revealed that seven characters exhibited direct positive effect and two characters showed negative direct effects on seed yield per plot, respectively. Biological yield per plot exhibited maximum positive direct effect (1.07) on seed yield followed by harvest index (0.854), days to 50 percent flowering $(0,009)$, pods per plant $(0.005)$, plant height $(0.004)$, days to maturity $(0.003)$ and primary branches (0.0024). .Seed weight exhibited maximum negative direct effect $(-0.024)$ on seed yield followed by seeds per pod (0.015). Days to 50 per cent flowering (0.009) showed minimal positive direct effect on seed yield per plot but showed negative indirect effect through biological yield per plot (-0.152), harvest index (-0.009) and 100seed weight $(-0.016)$. In the present study, days to maturity (0.003) had positive direct effect on seed yield per plot but had negative indirect effect via biological yield per plot (-0.124), 100-seed weight $(-0.014)$, harvest index (0.004) and primary branches(-0.0005). Plant height had a small positive direct effect $(0.0004)$ but expressed a negative indirect effect on seed yield via 100 -seed weight $(-0.0015)$ and primary branches(-0.0002). Seeds per pod (-0.0152) although had negative direct effect on seed yield but had positive indirect effect via biological yield per plot (0.170) and 100-seed weight (0.008). Biological yield per plot had a high positive direct effect (1.07) but also showed negative indirect effect on seed yield per plot via harvest index (-0.441) and seeds per pod (-0.002).100-seed weight had negative direct effect on seed yield but it showed positive indirect effect through days to 50 percent flowering $(0.0065)$, seeds per pod (0.005) and days to maturity. Tadesseet al (2014) evaluated twelve germplasm lines of lentil in Ethiopia and reported positive direct effect of pods per plant, seeds per pod on seed yield whereas, plant height and days to maturity had negative direct effect on seed yield .In another study on lentil conducted at Faizabad, Sharma et al (2014)observed that biological yield per plant (0.638), pods per plant (0.286) and harvest index (0.198) exerted positive direct effect on seed yield.

In the present study, path analysis revealed that biological yield per plot, harvest index, and number of pods per plant are the important yield component traits. The residual (unexplained) variation in the path analysis came out to be 0.58 based on phenotypic correlations among the characters studied for all the genotypes. This residual variation signified that there was still unexplained and unaccounted variation left among the genotypes which could not be explained by the above traits studied. To explain the same, some more morpho-physiological characters such as leaf area index and crop growth rate need to be studied. The plants with optimum leaf area give high biological yield.

\section{Conclusion}

In the present investigation it was concluded that the genetic differences between all the Recombinant Inbred Lines (RILs) were highly significant for all the traits under study. The biological yield per plot, harvest index, and number of pods per plant were identified as the prime seed yield contributing characters. These characters are significantly and positively correlated with yield, therefore their direct selection would be effective in improvement of seed yield in lentil. Path coefficient analysis revealed that traits like biological yield per plot(1.070), harvest index (0.854), days to 50 percent flowering $(0.009)$, days to maturity (0.003), plant height(0.004), pods per plant (0.005)and primary branches (0.0024) had positive direct effect on seed yield. So these are important yield contributing traits and emphasis should be given on such traits for deriving high yielding RILs of lentil. As Recombinant Inbred Lines are fixed in nature, 
identification of superior RILs possessing more number of pods per plant, branches per plant, higher 100- seed weight as well as rust resistance could be used as potential donors in the hybridization programme of lentil. This would further help in improving the seed yield potential of existing varieties of lentil being cultivated in Punjab.

\section{REFERENCES}

Al-Jibouri, H.A., Millar, P.A. and Robinsen, H.F. (1958). Genotypic and environmental variance and co-variances in an upland cotton crop of interspecific origin. Agron., J.50:633-36

Bicer, B.T. and Sarkar, D. (2008) Heritability and path analysis of some economical characteristics in lentil. J Central Eur Agric., 9:191-196

Dalbeer, Nath, S., Verma, O.P., Kavita, Kumar, K. (2015). Correlation and path coefficient analysis for yield attributes in lentil. International journal of science and research, 4(8):158-160

Dewey, D.R. and Lu, K.H. (1959). Correlation and path coefficient analysis of crested wheat grass seed production. Agronomy J., 51: 515-518

Kumar, N., Chahota, R.K. and Sood, B.C. (2009). Component analysis for seed yield and yield traits in microsperma $\times$ macrosperma derivatives of lentil (lens culinaris Medik.) Agric Sci Digest, 29: 163-168

Kumar, R., Kumar, M., Dogra, R.K. and Bharat, N.K. (2015).Variability and character association studies in garden pea during winter season at mid hills of Himachal Pradesh. Legume Research, 38(2): 164-168

Muehlbauer, F. J., Clement, W. J., and Summerfield, R. J. (1994). Production and breeding of lentil. Advances Agron.,54:315-16

SAS (1996). SAS / STAT software: Changes and Enhancements through Release 6.11. SAS Inst. Inc., Cary. NC.

Sharma, V., Paswan, S.K., Singh, V. and Khandagale, S. (2014). Correlation and path coefficient analysis of economically important traits in lentil. The Bioscan, 9 (2): 819-822

Singh, P., Singh, R., Kumar, K. and Singh, D.K. (2012).Estimates of genetic parameters in diverse genotypes of lentil. J Food Leg., 25:66-69

Singh, S., Singh, I., Gill, R.K., Kumar, S. and Sarker, A. (2009).Genetic studies for yield and component characters in large seeded exotic lines of lentil. J Food Leg., 22:229-232

Singh, U. and Srivastava, R.K. (2013).Genetic variability, heritability, interrelationships association and path analysis in lentil (Lens culinaris Medik.). Trends in Biosci., 6:277-280

Singla, R., Sharma, P. and Brar, J.S. (2007) Genetic studies for physiological traits and their relationship with seed yield in lentil. $J$ Food Leg., 20: 29-32

Tadesse, T., Leggesse, T., Mulugeta, B. And Sefera, G. (2014). Correlation and path coefficient analysis of yield and yield components in lentil germplasm in highlands of Bale, Ethiopia. Int. J. Biodivers. Conserv., 6(1): 115120 